\title{
TOXIDEZ, DEGRADAÇÃO NO MEIO AMBIENTE E MÉTODOS ELETROANALÍTICOS DE DETECÇÃO DO PESTICIDA CARBARIL
}

GUSTAVO STOPPA GARBELLINI*
CAROLINA VENTURINI ULIANA**

Este artigo apresenta breve revisão de literatura sobre o inseticida carbaril, muito utilizado na agricultura brasileira. Foram abordados seus efeitos tóxicos em humanos e animais, bem como sua degradação no meio-ambiente. Explorou-se a determinação de seus resíduos por métodos eletroanalíticos, utilizando os eletrodos de platina, mercúrio, diamante dopado com boro e eletrodos modificados, tais como os biossensores. O conhecimento das formas de degradação possibilita a elaboração de processos físicos e químicos visando o tratamento de águas e solos poluídos. Além disso, devido ao uso intenso do carbaril em culturas de frutas e vegetais, também é necessário o desenvolvimento de metodologias sensíveis para a detecção de resíduos nesses alimentos.

PALAVRAS-CHAVE: CARBARIL; TOXIDEZ; DEGRADAÇÃO; DETECÇÃO ELETROANALÍTICA.

* Doutorando em Química Analítica, Universidade de São Paulo, Instituto de Química de São Carlos, SP (e-mail: gustgarb@yahoo.com.br).

** Mestranda em Química Analítica, Universidade Estadual Paulista, Instituto de Química de Araraquara, SP (e-mail: uliana@iq.unesp.br). 


\section{INTRODUÇÃO}

Há várias décadas, os agroquímicos foram introduzidos nas plantações visando à proteção contra pestes. Devido à resistência das pestes aos produtos químicos, a cada ano grandes quantidades de novos compostos são usadas para proteger as colheitas causando efeitos indesejáveis e aumentando os custos da produção de alimentos. O uso de agroquímicos permanece como prática comum, especialmente em regiões tropicais (CARVALHO, 2006). Os pesticidas são venenos intencionalmente dispersados no ambiente para controlar pestes, mas também atuam sobre outras espécies causando sérios efeitos paralelos em espécies não-alvos. Resíduos de pesticidas podem persistir em solos, águas e alimentos, contaminando humanos e animais (CARVALHO, 2006).

Segundo o Sindicato Nacional da Indústria de Produtos para Defesa Agrícola (SINDAG), as vendas de pesticidas no Brasil em 2006 totalizaram 3,920 bilhões de dólares. O Estado de São Paulo destaca-se como o maior consumidor, representando $21,7 \%$ das vendas nacionais em termos de produto comercial e $20,6 \%$ em valor (808,2 milhões de dólares). Em seguida, aparecem os Estados de Mato Grosso (17,9\%), Paraná (13,4\%), Rio Grande do Sul (10,4\%), Minas Gerais (9,0\%), Goiás (8,8\%), Bahia (6,0\%) e Mato Grosso do Sul (4,7\%). Os demais Estados juntos compreenderam 9,2\% (SINDAG, 2007).

Os carbamatos, usados como inseticidas e herbicidas, encontram-se entre as classes de pesticidas mais utilizadas no Brasil. Esses compostos são muito instáveis em condições neutras e alcalinas em temperatura ambiente. O profam, primeiro representante dessa classe, foi seguido pelo clorprofam, barbam, asulam, carbutilato e clorbufam. Essas substâncias são sais ou ésteres do ácido carbônico com substituições dos hidrogênios hidroxílicos e amínicos por átomos, grupos funcionais ou radicais (GALLI et al., 2006).

Entre os principais compostos carbamatos encontra-se o pesticida carbaril (1-naftil metilcarbamato), inseticida de largo espectro, usado para controlar mais de 100 espécies em culturas (como citrus, nozes e tomate), gramados e florestas, sendo também usado como moluscicida e acaricida (EXTONET, 2007). Desde 1995, o governo do Reino Unido admite a existência de ligações entre o câncer e o carbaril. Em adição, a organização relacionada ao ambiente The Pesticides Trust pretende colocar a expressão "potencial carcinógeno humano" nas etiquetas dos produtos contendo carbaril (GHAUCH et al., 2001).

Diante da problemática exposta, o conhecimento da toxidez, da decomposição no ambiente e o desenvolvimento de métodos precisos de quantificação de resíduos de carbaril em águas, solos e alimentos tornaram-se de fundamental importância. Este artigo apresenta os aspectos toxicológicos, a degradação no ambiente e algumas metodologias eletroanalíticas de determinação de resíduos desse inseticida em diversas amostras.

\section{EFEITOS TOXICOLÓGICOS}

O carbaril apresenta moderada a elevada toxicidade, podendo produzir efeitos adversos em humanos pelo contato com a pele, inalação ou ingestão. Em níveis moderados a substância pode causar queimaduras. A inalação ou ingestão de largas quantidades pode ser tóxica aos nervos e aos sistemas respiratórios, resultando em náuseas, problemas estomacais, diarréia e salivação excessiva. A exposição dos humanos ao carbaril e a outros carbamatos causa a inibição da enzima acetilcolinesterase (AChE), essencial para transmissão de impulsos nervosos (GALLI et al., 2006).

A dose oral letal (LD50) para o carbaril em ratos enquadra-se entre 250 a $850 \mathrm{mg} \mathrm{Kg}^{-1}$ e de 100 a $650 \mathrm{mg} \mathrm{Kg}^{-1} \mathrm{em}$ camundongos (EXTONET, 2007). Baixas doses do produto podem causar irritação na pele e nos olhos de coelhos (EXTONET, 2007). Nenhum efeito foi observado na reprodução de ratos durante longo estudo com altas doses de carbaril. Da mesma forma, a exposição crônica dos animais ao composto não causa efeitos teratogênicos. $O$ carbaril também não é considerado como provável mutagênico em humanos. Muitos animais e também os humanos conseguem destruir a molécula do carbaril e rapidamente excretam o produto pela urina e fezes. As pessoas expostas ao carbaril por inalação excretam $74 \%$ da dose inalada pela urina na forma de subprodutos. O metabolismo de $85 \%$ do 
composto ocorre no prazo de 24 horas após a administração (EXTONET, 2007; PAN, 2007; IPCS, 2007). O carbaril é praticamente não-tóxico às espécies de pássaros selvagens, moderadamente tóxico para organismos aquáticos e letal para muitos insetos "não-alvos", incluindo abelhas e insetos benéficos ao ambiente (PAN, 2007; IPCS, 2007).

Na literatura especializada são encontrados trabalhos relacionados à toxicidade do carbaril em ratos (PADILHA et al., 2007; MORENO et al., 2007) que incluem prejuízos a respiração celular (tóxico para mitocôndrias em altas concentrações) e inibição da enzima AChE. Estudos sobre a toxidez do inseticida em algas verdes (MA et al., 2006), espécies aquáticas (FERRARI et al., 2004), peixes (FERRARI, VENTURINO e DE D'ANGELO, 2004), anfíbios (RELYEA, 2006) e insetos (MORA et al., 2000) são também relatados. Em trabalho interessante, KRISHNAMURTHI, DEVI e CHAKRABARTI (2006) determinaram o potencial da lesão do DNA e a genotoxicidade de vários pesticidas presentes em solos contaminados. Os efeitos tóxicos mais significativos foram devidos ao carbaril e ao \pm -naftol, maiores constituintes das amostras de solos contaminados.

\section{DEGRADAÇÃO NO AMBIENTE}

\section{1 ÁGUAS}

Em água pura e esterilizada, mantida sob proteção de luz, a persistência do carbaril depende do $\mathrm{pH}$, sendo mais estável em condições ácidas. Seu tempo de meia-vida em pH 7 é de 10 a 16 dias, em pH 8 de aproximadamente 2 dias e em valores de $\mathrm{pH}$ maiores que 8 , esse tempo é de algumas horas. $\mathrm{O}$ carbaril pode ser prontamente hidrolizado em água, sendo estabelecido o equilíbrio ácido-base. Os conjugados do carbamato sofrem reação de eliminação, gerando ácidos carbâmicos instáveis que se decompõem a aminas primárias e $\mathrm{CO}_{2}$. Entretanto, a principal via de degradação não-biológica do carbaril em água envolve a hidrólise catalisada por bases gerando o 1-naftol (EXTONET, 2007; IPCS, 2007).

Há evidências suficientes de que a fotodecomposição contribui para a degradação do carbaril em águas claras de superfícies, expostas a luz do sol por longos períodos. Em águas turvas, cuja penetração da luz é drasticamente reduzida, a fotólise oferece apenas pequena contribuição na decomposição do pesticida. A degradação microbiana do carbaril em águas naturais tem sido considerada como a segunda rota de decomposição do produto, depois da hidrólise química (IPCS, 2007).

O uso do carbaril na agricultura pode indiretamente produzir resíduos em águas superficiais e nos sedimentos do solo, como resultado de ventos ou interações com partículas do solo. $\mathrm{O}$ pesticida geralmente não persiste no meio ambiente aquático por ser estável à hidrólise em águas ácidas, mas é altamente suscetível a esse processo em águas mais alcalinas. A degradação mediada biologicamente e a fotólise são mecanismos secundários. Sabe-se que substâncias húmicas e sedimentos influenciam a persistência do carbaril em sistemas aquáticos. Em muitos casos, metade da concentração do carbaril presente em águas naturais é degradada em poucos dias ou até mesmo em menos que um dia. Pela baixa persistência em água e rápida degradação por organismos vivos, o carbaril tem baixas propriedades de bioacumulação e não representa riscos de biomagnificação da contaminação sob condições práticas (EXTONET, 2007; IPCS, 2007). Deve-se ressaltar que resíduos de carbaril têm sido encontrados e monitorados em águas naturais (FYTIANOS, PITARAKIS e BOBOLA, 2006; DE LLASERA e BERNAL-GONZALEZ, 2001).

\subsection{SOLOS E VEGETAÇÃO}

As propriedades de adsorção/desorção e a baixa persistência do carbaril no solo indicam moderada mobilidade e que o produto permanece em suas camadas superiores quando aplicado em doses normais na agricultura. A degradação da substância no solo ocorre como resultado da atividade de microorganismos e por meio de efeitos físicos e químicos. O pesticida é submetido à hidrólise, oxidação e a outros processos químicos como, por exemplo, a fotólise. No campo, sob climas temperados e quentes, o tempo de meia-vida do pesticida não excede a um mês (IPCS, 2007). 
Alguns estudos têm demonstrado a grande habilidade dos microrganismos em degradar o carbaril presente no solo (KUO e REGAN, 1992). Os organismos mais freqüentemente identificados são bactérias (Pseudomonas phaseolicola, P.cepaphia e Rhodococcus sp.) e fungos (Aspergillus niger, A. terreus, Fusarium solani e Gilocladium roseum). Em muitos casos foi demonstrado que a persistência do carbaril no solo decresce após a primeira aplicação, e que quantidades do inseticida podem ser encontradas devido à aplicação na forma de spray ou pela lavagem de áreas tratadas pela chuva (IPCS, 2007).

A decomposição do carbaril em plantas depende das condições climáticas, sendo mais rapidamente decomposto em altas temperaturas e por excessiva radiação ultravioleta. Níveis residuais do composto em pastagens são mais baixos em regiões com climas quentes em relação a outras regiões (EXTONET, 2007; IPCS, 2007).

BONDARENKO e GAN (2004) estudaram a degradação de pesticidas organofosforados e carbamatos em sedimentos de córregos urbanos na Califórnia. Particularmente para o carbaril foi observada rápida dissipação sob condições aeróbicas (tempo de meia-vida de 1,8 a 4,9 dias) e que o produto se tornou não-degradável sob condições anaeróbicas (tempo de meia-vida de 125 a 746 dias). Alguns trabalhos a respeito da adsorção, mobilidade e persistência do carbaril em solos também são encontrados (ALI, RATHORE e SINGH, 2000; HASTINGS et al., 1998).

\section{MÉTODOS ELETROANALÍTICOS PARA DETECÇÃo DE RESÍDUOS}

Diversas metodologias analíticas têm sido propostas para se determinar resíduos de carbaril em diferentes matrizes. As técnicas cromatográficas, entre elas a cromatografia a líquido de alta eficiência (CLAE) e a cromatografia a gás (CG) (HANTASH et al., 2006; PETROPOULOU et al., 2006; NUNES et al, 1998) são as mais utilizadas. As técnicas cromatográficas são importantes na análise química em função de sua capacidade para efetuar separações, identificar e quantificar espécies presentes em amostras mediante detectores específicos, tais como ultravioleta-vísivel, ionização por chama e fluorescência, entre outros (GALLI et al., 2006). A quantificação de compostos orgânicos utilizando essas técnicas fornece resultados com limites de deteç̧ão (LD) na faixa de nanogramas a microgramas $/ \mathrm{L}\left(\mathrm{ng} \mathrm{L}^{-1} / \mu \mathrm{g} \mathrm{L}^{-1}\right)$, dependendo da técnica de extração e do detector. Apesar das características vantajosas, as técnicas cromatográficas dependem de longo tempo de preparo de amostras, exigem grande quantidade de reagentes e a instrumentação é relativamente cara. Tal fato despertou o interesse pela detecção e quantificação de pesticidas por técnicas eletroanalíticas que, além de simples e de baixo custo, oferecem a possibilidade de se determinar a concentração do analito diretamente na amostra sem pré-tratamento ou separação química (GALLI et al., 2006). Em geral, as respostas eletroanalíticas sofrem menor influência de interferentes presentes nas amostras, possibilitando o uso dessas técnicas na análise de pesticidas (GALLI et al., 2006; GARRIDO et al., 2004).

$\mathrm{Na}$ escolha do material do eletrodo de trabalho deve-se considerar que as respostas obtidas estão relacionadas com as reações redox que ocorrem em sua superfície ou na interface eletrodosolução. Desta forma, o analito de interesse pode interagir com a superfície eletródica e resultar na transferência de elétrons. Um dos eletrodos mais empregados para a detecção de pesticidas é o de mercúrio, porém esse metal apresenta elevada toxicidade e não pode ser utilizado em intervalo de potenciais positivos. Assim, eletrodos sólidos como os de platina, ouro, carbono, níquel, ferro e cobre que apresentam janela de potencial positiva têm considerável aplicabilidade em determinações analíticas (GALLI et al., 2006). Outro tipo de eletrodo sólido que vêm sendo usado para detecção de pesticidas é o de diamante dopado com boro (DDB), devido as suas propriedades particulares (extensa janela eletroquímica, grande resistência a vários meios agressivos e baixas correntes capacitivas) (SUFFREDINI, MACHADO e AVACA, 2004).

É possível realizar modificação na superfície eletródica quando a transferência é muito lenta, não ocorre, ou ocorre com valor de potencial fora da janela de potencial do eletrodo. A imobilização de grupos funcionais, incorporação de catalisadores inorgânicos e biológicos (enzimas e anticorpos), 
deposição de filmes poliméricos, modificação com sílica e deposição de membranas biológicas têm sido usados para melhorar a resposta final. Como o analito irá interagir diretamente com o agente modificante, os eletrodos quimicamente modificados são mais seletivos e mais sensíveis que os eletrodosbase. A modificação possibilita controlar a natureza físico-química da interface eletrodo-solução como forma de alterar a reatividade e seletividade do eletrodo-base, favorecendo o desenvolvimento de eletrodos para diferentes aplicações analíticas. As modificações de superfícies eletródicas tornaram-se importantes, pois são específicas para determinado tipo de analito e promovem alto grau de seletividade. É possível desenvolver sensores de fácil manipulação e construção, baixo custo, potencial de miniaturização do sistema e detecção rápida (GALLI et al., 2006). Desta forma, a utilização de agentes modificantes constitui alternativa para a substituição de eletrodos de mercúrio e metais inertes. A construção de biossensores baseia-se na inibição da atividade de enzimas específicas, que são freqüentemente empregadas na detecção de pesticidas carbamatos.

Foram encontrados vários trabalhos a respeito da determinação de resíduos de carbaril mediante métodos eletroanalíticos, envolvendo a utilização de biossensores. SKLADAL et al. (1997) desenvolveram biossensores para a determinação de carbamatos (aldicarb, carbaril, carbofuran, metomil e propoxur) em vegetais, baseados em cinco diferentes colinesterases como elementos de reconhecimento e eletrodos impressos como transdutores amperométricos. O desempenho dos biossensores foi avaliado em extratos de batatas e cenouras e comparado ao procedimento padrão envolvendo medidas cromatográficas (CLAE). O biossensor foi usado com sucesso para análise direta dos pesticidas em sucos de vegetais sem as etapas de pré-tratamentos. TOSCANO et al. (2000) utilizaram o teste imunoenzimático ELISA (Enzyme Linked Immunosorbent Assay), aplicado no diagnóstico de doenças infecciosas para análise de resíduos de pesticidas, devido sua alta sensibilidade e seletividade. Entretanto, esse método pode ser afetado por componentes da matriz. Nesse trabalho, o teste para o carbaril em amostras de águas foi analisado pela interferência natural de ácidos fúlvicos. Os resultados sugeriram que a alta concentração de ácidos e as condições de $\mathrm{pH}$ ácidos $(\mathrm{pH} 4,0)$ interferem no sinal, diminuindo a sensibilidade do método de deteç̧ão. A diluição das amostras e ajuste para pH 8,0 são apropriados para minimizar as interferências da matriz no teste ELISA.

LEE et al. (2001) desenvolveram biossensor potenciométrico, baseado na injeção em fluxo para a determinação de pesticidas carbamatos. O princípio do biossensor baseou-se na inibição da enzima AChE pelos pesticidas. Todos esses compostos em concentrações de 1,0 x 10-6 $\mathrm{mol} \mathrm{L}^{-1}$ inibiram o sensor enzimático, demonstrando a utilidade do método. $O$ tratamento para regeneração enzimática com piridina-2-aldoxima permitiu o uso repetido do sensor. Curvas analíticas para o carbaril e para o carbofurano no intervalo de concentração de $10^{-11}$ a $10^{-4} \mathrm{~mol} \mathrm{~L}^{-1}$ foram obtidas com LD de $10^{-10}$ e $10^{-11} \mathrm{~mol} \mathrm{~L}^{-1}$, respectivamente. NUNES, JEANTY e MARTY (2004) compararam vários procedimentos de imobilização da enzima AChE em eletrodos de grafite modificados com 7,7,8,8tetracianoquinodimetano (TCNQ). Os métodos de imobilização empregando cross-linking com glutaraldeído na presença da proteína albumina de soro bovino e a fotopolimerização com poli(vinil álcool) levaram a formação de grupos stirilpiridinium (PVA-SbQ). Inicialmente, a reação enzimasubstrato foi realizada e os parâmetros monitorados por cronoamperometria e coulometria: intensidades de corrente, tempo de estabilização da resposta de corrente e a transferência de massa representada pela carga Coulomb. Os biossensores foram usados para ensaios de inibição e para verificar a sensibilidade em relação aos pesticidas aldicarb, carbaril, carbofurano e metomil. Os limites de detecção foram determinados com o mínimo de inibição e variaram de $10^{-9}$ a $8 \mathrm{x}$ $10^{-9} \mathrm{~mol} \mathrm{~L}^{-1}\left(0,2\right.$ a $\left.1,5 \mathrm{\mu g} \mathrm{L}^{-1}\right)$ empregando a imobilização da enzima por meio da fotopolimerização com PVA-SbQ. Na prática, os autores observaram que esse tipo de imobilização é mais simples e produz melhores resultados evidenciando excelente sensibilidade para metilcarbamatos.

Estudo comparativo, usando eletrodos impressos modificados com Co-ftalocianina e azul da Prússia (corante), foi realizado por ARDUINI et al. (2006). Ambos os eletrodos apresentaram facilidade na preparação e alta sensibilidade a tiocolina com potencialidades para a detecção dos pesticidas. As enzimas acetilcolinesterase e butirilcolinesterase (BChE) foram usadas e o efeito de inibição dos diferentes pesticidas estudado. Os biossensores a base de AChE mostraram alta sensibilidade aos pesticidas aldicarb ( $50 \%$ de inibição com $50 \mu \mathrm{g} \mathrm{L}^{-1}$ ) e ao carbaril ( $50 \%$ de inibição com $\left.85 \mu \mathrm{g} \mathrm{L}^{-1}\right)$. BUCUR et al. (2006) mostraram a construção de biossensor 
amperométrico para a detecção de pesticidas carbamatos baseado na inibição da enzima AChE. A enzima foi imobilizada em matriz sol-gel em eletrodos impressos modificados com TCNQ. A atividade enzimática foi estimada pela medida da tiocolina produzida pela hidrólise da acetiltiocolina, usando o TCNQ como mediador. As enzimas acetilcolinesterases, provenientes da Drosophila melanogaster (drosófilas) foram escolhidas para aumentar a sensibilidade em relação aos pesticidas e evidenciaram melhora substancial nos limites de detecção se comparados às colinesterases de outras fontes. Três enzimas mutantes foram testadas contra os inseticidas carbaril, carbofurano e pirimicard. Particularmente para o carbaril, o melhor LD foi obtido com a enzima mutante $Y 370 \mathrm{~A}\left(1 \times 10^{-8} \mathrm{~mol} \mathrm{~L}^{-1}\right)$. Esses biossensores foram aplicados para análises em dois tipos de água potável.

PEREZ-LOPEZ et al. (2004) analisaram o carbaril após a oxidação do composto a 1,4naftoquinona em águas naturais e solos. A oxidação do carbaril foi estudada com eletrodo de platina e solução tampão $\mathrm{BR} 0,024 \mathrm{~mol} \mathrm{~L}^{-1}(\mathrm{pH} \mathrm{7,0)}$ como eletrólito suporte. A redução do produto da oxidação 1,4-naftoquinona sobre o eletrodo gotejante de mercúrio foi usada na determinação indireta do carbaril por polarografia de pulso diferencial após a separação em cartuchos C-18 (LD: $0,41 \mathrm{mg} \mathrm{L}^{-1} \mathrm{em}$ água e $0,47 \mathrm{mg} \mathrm{kg}^{-1} \mathrm{em}$ solos) e diretamente sem separação por voltametria de redissolução adsortiva (LD: $5 \mu \mathrm{g} \mathrm{L}^{-1}$ e $7 \mu \mathrm{g} \mathrm{Kg}^{-1} \mathrm{em}$ solos).

Eletrodos de DDB foram usados por RAO et al. (2002) em dois tipos de detecção, após separação por cromatografia a líquido. Primeiro usaram detecção direta dos pesticidas nãoderivatizados em valor de potencial de $1,45 \mathrm{~V}$ vs $\mathrm{Ag} / \mathrm{AgCl}$ (eletrodo de referência), resultando em LD de 5-20 $\mu \mathrm{g} \mathrm{L}^{-1}$. No segundo método, os limites de detecção foram melhorados, submetendo os pesticidas à hidrólise alcalina como etapa prévia. Os derivados fenólicos gerados oxidam em menor valor de potencial $(0,9 \mathrm{~V}$ vs $\mathrm{Ag} / \mathrm{AgCl})$, aumentando significativamente a sensibilidade. Esse método apresentou LD de 0,6-1 $\mu \mathrm{g} \mathrm{L}^{-1}$. O eletrodo de DDB era reativado por tratamento anódico de 3,0 V por 30 minutos em casos de inativação da superfície devido à adsorção de produtos da oxidação dos pesticidas. A vantagem desse eletrodo para a detecção de compostos fenólicos consiste em oferecer maior estabilidade em comparação com outros eletrodos como, por exemplo, o de carbono vítreo. CODOGNOTO et al. (2006) estudaram o comportamento voltamétrico anódico do carbaril (sem a derivatização) sobre o eletrodo de DDB em soluções aquosas. O LD obtido pela voltametria de onda quadrada (SWV) no intervalo de concentração de 2,5 a $30,0 \times 10^{-6} \mathrm{~mol} \mathrm{~L}^{-1}$ foi de $8,2 \mu \mathrm{g} \mathrm{L}^{-1} \mathrm{em}$ água pura (eletrólito suporte). Quando aplicado em águas de um córrego da cidade de São Carlos (SP) em vários pontos de poluição houve diminuição na sensibilidade do método de detecção do pesticida, entretanto, os níveis de recuperação mostraram-se satisfatórios.

\title{
5 CONCLUSÃO
}

A degradação do carbaril no solo e em águas ocorre devido à atividade de microorganismos e por meio de efeitos físicos e químicos como, fotodecomposição e hidrólise. O uso intenso do carbaril na agricultura, tóxico ao ambiente e aos humanos, polui águas, solos e alimentos, justificando a necessidade de se monitorar seus resíduos nessas matrizes. Vantagens como o baixo custo das análises e os baixos valores dos limites de detecção mostram a possibilidade da utilização de métodos eletroanalíticos na detecção de pesticidas, visando determinar concentrações em níveis cada vez menores.

\author{
ABSTRACT \\ TOXICITY, ENVIRONMENTAL DEGRADATION AND ELECTROANALYTICAL \\ METHODS FOR THE DETECTION OF THE CARBARYL PESTICIDE \\ This paper presents a brief literature review about the carbaryl insecticide, widely used in the Brazilian agriculture. \\ Were discussed it's toxic effects in humans and animals, and its degradation in the environment. The
}


etermination of their residues through electroanalytical methods using platinum, mercury, boron-doped diamond electrodes and modified electrodes such as biosensors were also reported. The knowledge of the degradation pathways allows the elaboration of physical and chemical processes yielding the treatment of polluted water and soils. Moreover, due the intensive use of carbaryl in fruits and vegetables crops, it is also necessary the development of sensitive methodologies for the detection of their residues in these foods.

KEY-WORDS: CARBARYL; TOXICITY; DEGRADATION; ELECTROANALYTICAL DETECTION.

\section{REFERÊNCIAS}

11 ALI, I.; RATHORE, H. S.; SINGH, K. K. Studies on adsorption of carbaryl as influenced by soil organic matter (SOM) and other soil characteristics. J. Indian Chem. Soc., v. 77, n. 1, p. 17-19, 2000.

2 ARDUINI, F.; RICCI, F.; TUTA, C. S, MOSCONE, D.; AMINE, A.; PALLESCHI, G. Detection of carbamic and organophosphorous pesticides in water samples using a cholinesterase biosensor based on Prussian Blue-modified screenprinted electrode. Anal. Chim. Acta, v. 580, n. 2, p. 155-162, 2006.

3 BONDARENKO, S.; GAN, J. Y. Degradation and sorption of selected organophosphate and carbamate insecticides in urban stream sediments. Environ. Toxicol. Chem., v. 23, n. 8, p. 1809-1814, 2004.

4 BUCUR, B.; FOURNIER, D.; DANET A.; MARTY, J. L. Biosensors based on highly sensitive acetylcholinesterases for enhanced carbamate insecticides detection. Anal. Chim. Acta, v. 562, n. 1, p. 115-121, 2006.

5 CARVALHO, F. P. Agriculture, pesticides, food security and food safety. Environ. Sci. Policy, v. 9, n. 7-8, p. 685-692, 2006.

6 COdOGNOTO, L.; TANIMOTO, S. T.; PEDROSA, V. A.; SUFFREDINI, H. B.; MACHADO, S. A. S.; AVACA, L. A. Electroanalytical determination of carbaryl in natural waters on boron doped diamond electrode. Electroanalysis, v.18, n. 3, p. 253-258, 2006.

7 DE LLASERA, M. P. G.; BERNAL-GONZALEZ, M. Presence of carbamate pesticides in environmental waters from the northwest of Mexico: determination by liquid chromatography. Water Res., v. 35, n. 8, p. 1933-1940, 2001.

8 EXTONET. The Extension Toxicology Network. Pesticide information profile. Disponível em: http://extoxnet.orst.edu/ pips/carbaryl.htm. Acesso em: 5 mar. 2007.

9 FERRARI, A.; ANGUIANO, O. L.; SOLEÑO, J.; VENTURINO, A.; DE D'ANGELO, A. M. P. Different susceptibility of two aquatic vertebrates (Oncorhynchus mykiss and Bufo arenarum) to azinphos methyl and carbaryl. Comp. Biochem. Physiol., Part C: Toxicol. Pharmacol., v. 139, n. 4, p. 239-243, 2004.

10 FERRARI, A.; VENTURINO, A.; DE D'ANGELO, A. M. P. Time course of brain cholinesterase inhibition and recovery following acute and subacute azinphosmethyl, parathion and carbaryl exposure in the goldfish (Carassius auratus). Ecotoxicol. Environ. Saf., v. 57, n. 3, p. 420-425, 2004.

11 FYTIANOS, K.; PITARAKIS, K.; BOBOLA, E. Monitoring of N-methylcarbamate pesticides in the Pinios River (Central Greece) by HPLC. Int. J. Environ. Anal. Chem., v. 86, n. 1-2, p. 131-145, 2006.

12 GALLI, A.; DE SOUZA, D.; GARBELLINI, G. S.; COUTINHO, C. F. B.; MAZO, L. H.; AVACA, L. A.; MACHADO, S. A. S. Utilização de técnicas eletroanalíticas na determinação de pesticidas em alimentos. Quim. Nova, v. 29, n. 1, p. 105-112, 2006.

13 GARRIDO, E. M.; DELERUE-MATOS, C.; LIMA, J. L. F. C.; BRETT, A. M. O. Electrochemical methods in pesticides control. Anal. Lett., v. 37, n. 9, p. 1755-1791, 2004.

14 GHAUCH, A.; GALLET, C.; CHAREF, A.; RIMA, J.; MARTIN-BOUYER, M. Reductive degradation of carbaryl in water by Zero-valent iron. Chemosphere, v. 42, n. 4, p. 419-424, 2001.

15 HANTASH, J.; BARTLETT, A.; OLDFIELD, P.; DÉNĖS, G.; O'RIELLY, R.; ROUDIERE, D.; MENDUNI, S. Use of an online imprinted polymer pre-column, for the liquid chromatographic-UV absorbance determination of carbaryl and its metabolite in complex matrices. J. Chromatogr. A, v. 1125, n. 1, p. 104-111, 2006.

16 HASTINGS, F. L.; WERNER, R. A.; SHEA, P. J.; HOLSTEN, E. H. Persistence of carbaryl within boreal, temperate and Mediterranean ecosystems. J. Econ. Entom., v. 91, n. 3, p. 665-670, 1998.

17 IPCS. International Programme on Chemical Safety. Carbaryl. Disponível em: http://www.inchem.org/documents/ehc/ ehc/ehc153.htm. Acesso em: 26 mar. 2007. 
18 KRISHNAMURTHI, K.; DEVI, S. S.; CHAKRABARTI, T. DNA damage caused by pesticide-contaminated soil. Biomed. Environ. Sci., v. 19, n. 6, p. 427-431, 2006.

19 KUO, W. S.; REGAN, R. W. Degradation of carbaryl and 1-naphthol by spent mushroom compost microorganisms. Water Sci. Techn., v. 26, n. 9-11, p. 2081-2084, 1992.

20 LEE, H. S.; KIM, Y. A.; CHUNG, D. H.; LEE, Y. T. Determination of carbamate pesticides by a cholinesterase-based flow injection biosensor. Int. J. Food Sci. Techn., v. 36, n. 3, p. 263-269, 2001.

21 MA, J.; LU, N.; QIN, W.; XU, R.; WANG, Y.; CHEN, X. Differential responses of eight cyanobacterial and green algal species to carbamate insecticides. Ecotoxicol. Environ. Saf., v. 63, n. 2, p. 268-274, 2006.

22 MORA, B. R.; MARTíNEZ-TABCHE, L.; SÁNCHEZ-HIDALGO, E.; HERNÁNDEZ, G. C.; RUIZ, M. C. G.; MURRIETA, F. F. Relationship between toxicokinetics of carbaryl and effect on acetylcholinesterase activity in Pomacea patula Snail. Ecotoxicol. Environ. Saf., v. 46, n. 2, p. 234-239, 2000.

23 MORENO, A. J. M.; SERAFIM, T. L.; OLIVEIRA, P. J.; MADEIRA, V. M. C. Inhibition of mitochondrial bioenergetics by carbaryl is only evident for higher concentrations - relevance for carbaryl toxicity mechanisms. Chemosphere, v. 66, n. 3, p. 404-411, 2007.

24 NUNES, G. S.; JEANTY, G.; MARTY, J. L. Enzyme immobilization procedures on screen-printed electrodes used for the detection of anticholinesterase pesticides - comparative study. Anal. Chim. Acta., v. 523, n. 1, p. 107-115, 2004.

25 NUNES, G. S.; RIBEIRO, M. L.; POLESE, L.; BARCELÓ, D. Comparison of different clean-up procedures for the determination of $\mathrm{N}$-methylcarbamate insecticides in vegetable matrices by high-performance liquid chromatography with UV detection. J. Chromatogr. A, v. 795, n. 1, p. 43-51, 1998.

26 PADILLA, S.; MARSHALL, R.S.; HUNTER, D.L.; LOWIT, A., Time course of cholinesterase inhibition in adult rats treated acutely with carbaryl, carbofuran, formetanate, methomyl, methiocarb, oxamyl or propoxur. Toxicol. Appl. Pharmacol., v. 219, n. $2-3$, p. 202-209, 2007.

27 PAN. Pesticide Action Network. Carbaryl: identification, toxicity, use, water pollution potential, ecological toxicity and regulatory information. Dísponível em: http://www.pesticideinfo.org/Detail_Chemical.jsp?Rec_Id=PC32816. Acesso em: 26 mar. 2007.

28 PEREZ-LOPEZ, J. A.; ZAPARDIEL, A.; BERMEJO, E.; ARAUZO, E.; HERNÁNDEZ, L. Electrochemical determination of carbaryl oxidation in natural-water and soil samples. Fresenius J. Anal. Chem., v. 350, n. 10-11, p. 620-625, 1994.

29 PETROPOULOU, S. E.; GIKAS, E.; TSARBOPOULOS, A.; SISKOS, P. A. Gas chromatographic-tandem mass spectrometric method for the quantitation of carbofuran, carbaryl and their main metabolites in applicators' urine. J. Chromatogr. A, v. 1108, n. 1, p. 99-110, 2006.

30 RAO, T. N.; LOO, B. H.; SARADA, B. V.; TERASHIMA, C.; FUJISHIMA, A. Electrochemical detection of carbamate pesticides at conductive diamond electrodes. Anal. Chem., v. 74, n. 7, p. 1578-1583, 2002.

31 RELYEA, R. A. The effects of pesticides, pH, and predatory stress on amphibians under mesocosm conditions. Ecotoxicol., v. 15, n. 6, p. $503-511,2006$.

32 SINDAG. Sindicato Nacional da Indústria de Produtos para Defesa Agrícola. Defensivos: expectativa de aumento da demanda para 2007. Disponível em: http://www.sindag.com.br/upload/IEA-expectativaaumentodemanda.doc. Acesso em: 6 set. 2007.

33 SKLADAL, P.; NUNES, G. S.; YAMANAKA, H.; RIBEIRO, M. L. Detection of carbamate pesticides in vegetable samples using cholinesterase-based biosensors. Electroanalysis, v. 9, n. 14, p.1083-108, 1997.

34 SUFFREDINI, H. B.; MACHADO, S. A. S.; AVACA, L. A. The water decomposition reactions on boron-doped diamond electrodes. J. Braz. Chem. Soc., v. 15, n. 1, p. 16-21, 2004.

35 TOSCANO, I. A. S.; RIBEIRO, M. L.; ROCHA, J. C.; NUNES, G. S.; BARCELÓ, D. Determinação de carbaril utilizando testes ELISA (Enzyme-linked immunosorbent assay) e CLAE com detecção por arranjo de diodos. Quím. Nova, v. 23, n. 4, p. 466-471, 2000.

\section{AGRADECIMENTOS}

Os autores agradecem ao CNPq e a CAPES pelas bolsas e apoios financeiros concedidos. 